\title{
HEAT TRANSFER AND FRICTION CHARACTERISTICS OF AN ARRAY OF PERFORATED FINS UNDER LAMINAR FORCED CONVECTION
}

\author{
A. Ahmadi Nadooshan ${ }^{1, *}$, Sh. Mohammadi ${ }^{1}$, M. Bayareh ${ }^{1}$
}

\begin{abstract}
Three-dimensional incompressible laminar fluid flow and heat transfer of a heated array of circular perforated fins are examined numerically. The Navier-Stokes and energy equations are solved by a finite volume method using the SIMPLE algorithm. The second order upwind technique is employed to discretize the momentum and energy equations. Computations were performed for a range of Reynolds numbers $100 \leq \operatorname{Re} \leq$ 350. Thermal performance and effectiveness as well as friction coefficient of perforated and solid fins are determined for the optimum porosity. The results show that the average coefficient of friction reduces with increasing the Reynolds number and the number of perforations. The heat transfer rate increases with the porosity and the Reynolds number. It is found that perforated fin effectiveness decreases with the number of peroration at constant Reynolds numbers.
\end{abstract}

Keywords: Laminar Forced Convection, Perforated Fin, Nusselt Number, Reynolds Number, Thermal Performance

\section{INTRODUCTION}

Advanced technologies need high performance heat transfer equipment. Methods for improving heat transfer divided into two categories: active and passive methods [1]. Active methods require external power to enhance heat transfer and passive methods do not require external power. Extended surfaces or fins are example of passive methods that are commonly used in variety of industrial applications to enhance the rate of heat transfer between primary surface (heat sink) and ambient fluid. Nowadays, optimization is considered in designing of heat exchangers in a way that prices reduce and better performance results. Fin optimization can be performed by minimizing the weight of the fin for specific amount of heat transfer or enhancing the heat transfer for specific weight of the fin. One of the best ways to improve the performance of heat transfer is to use fins with perforation [2].

EI-Sayed et al. [3] performed an experimental investigation to study the heat transfer and pressure drop of a turbulent flow through an array of fins with rectangular perforations for three different orientation models: parallel flow, impinging flow, and reverse impinging flow. They showed that the parallel and impinging flows case have the most and the lowest effectiveness, respectively. Sahin and Demir [4] studied convection heat transfer from square-sectional perforated fins for the range of Reynolds number, $13500<R e<42000$. They found that optimum Reynolds number is the highest one, 42000 for lateral distance $51 \mathrm{~mm}$ between the fins.

Dhanawade et al. [5] experimentally investigated the heat transfer enhancement for lateral circular perforated fins under forced convection. They found that maximum porosity and Reynolds number have an important effect on heat transfer rate. Ravat and Patil [6] studied heat transfer as well as friction factor of perforated fins subjected to forced convection. They demonstrated that heat transfer of a perforated fin is considerably higher than that of a solid one due to a reduction in energy loss. Experimental investigation on heat transfer from an array of perforated fins was performed by Saadat et al. [7]. Circular perforated fins and flat surfaces were made of aluminum. They used different arrangements and found that the average heat transfer increases with the Reynolds number. It is also revealed that combination of cross and stream-wise perforations leads to higher heat transfer in comparison with the lateral perforations. Farhad Ismail et al. [8] studied turbulent forced convection heat transfer from circular and rectangular perforated fins. They showed that circular perforations usage results in enhancing heat transfer and decreasing pressure drop compared to the rectangular perforated fins. 
Shaeri and Yaghubi [9] numerically investigated the turbulent convection heat transfer from an array of rectangular perforated fins. They compared the results of perforated fins with those of solid ones and showed that specific factor for perforated fins is higher than solid ones. It is found that the eddy generation behind the fins decreases with the number of perforations. Their results showed that the reduction of Nusselt number is higher for the perforated fins than that of solid ones due to an increase in the surface of the fins. Ashjaee et al. [10] studied the forced convection heat transfer and pressure drop in the presence of magnetic field. They obtained an optimum condition and showed that a considerable increase occurs in heat transfer due to the magnetic field.

Shaeri and Bonner [11] experimentally investigated thermo-fluid characteristics of laminar forced convection flows over an array of perforated fins. They demonstrated that the flow interaction with each other is an important mechanism affects heat transfer rate. Wen and Yeh [12] numerically studied forced convection heat transfer for two different types of circular fins. They found that smaller hollow in the base plate concludes more effectiveness in cmparison with the larger one.

Mohammadi et al. [13] simulated laminar forced convection heat transfer from fins with circular and rectangular perforations and confirmed that circular perforated fins have higher effectiveness in comparison with the fins with rectangular perforations. Bayareh et al. [14] investigated the effect of geometry on the performance of a scraped surface heat exchanger. They introduced a new blade to develop the heat transfer. Maurya and Singh [15] studied isothermal flow around plates in a shell and tube heat exchanger to find the optimal design.

In this study, the rate of heat transfer and perforated fin effectiveness are calculated for an optimum porosity of the fins. The objective of the present work is to describe the thermo-fluid characteristics of the flow around an array of circular perforated fins to evaluate the effect of the porosity and the Reynolds number on laminar forced convection heat transfer.
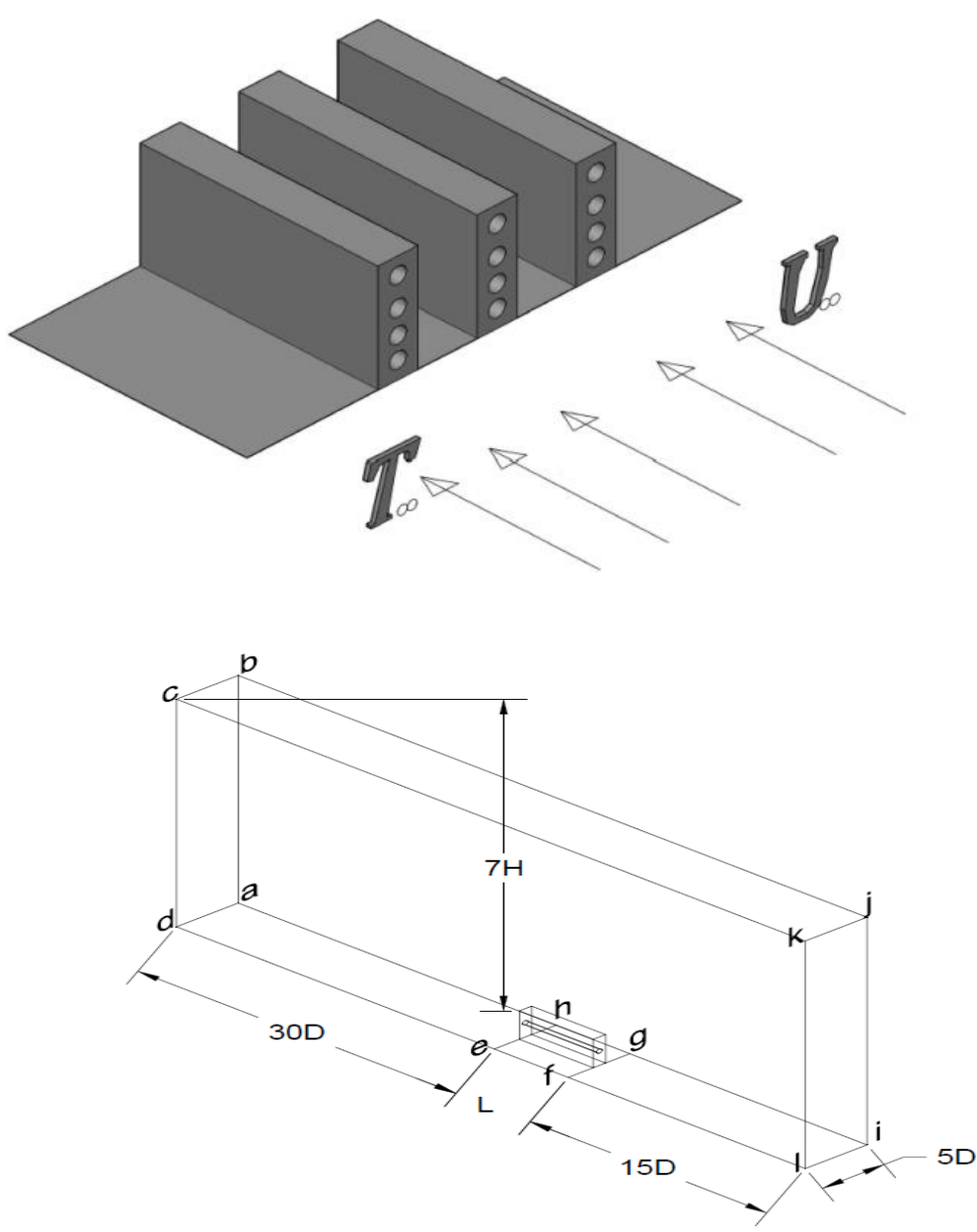

Figure 1. Schematic of the flow around a circular perforated fin. 


\section{MATHEMATICAL MODEL AND VALIDATION}

In this study, heat transfer and friction characteristics of a laminar flow around an array of perforated fins are presented (Fig. 1). The governing equations for steady-state incompressible laminar flow are continuity, Momentum and energy equations that are as follows, respectively:

$$
\begin{gathered}
\nabla \cdot \vec{U}=0 \\
\rho(\vec{U} \cdot \nabla \vec{U})=-\nabla P+\mu \nabla^{2} \vec{U} \\
\rho C_{P}(\vec{U} \cdot \nabla \vec{T})=k_{f} \nabla^{2} \vec{T}
\end{gathered}
$$

The average coefficient of friction and average Nusselt number are defined as follows, respectively:

$$
\begin{aligned}
& \bar{C}_{f}=\frac{\overline{\tau_{w}}}{1 / 2 \rho u^{2}} \\
& \overline{N u}=\frac{\bar{h}}{K} D
\end{aligned}
$$

Perforated fin effectiveness is defined to explore the thermal performance of the fins as follows:

$$
\varepsilon_{p f}=\frac{Q_{p f}-Q_{s f}}{Q_{s f}}
$$

An important factor in designing a thermal system is to reduce its weight and improve its performance. Parameter $M$ shows the rate of heat transfer per unit area of a perforated fin to that of a solid fin that is defined as follows:

$$
M=\frac{Q_{p f}}{V_{p}} / \frac{Q_{s f}}{V_{s}}
$$

It is helpful to calculate the drag force exerted on the fin to explore the hydrodynamics of the flow. To evaluate friction drag force, the following equation is used:

$$
\begin{gathered}
F_{F}=\sum\left(\tau_{w}\right)_{i} \times A_{F} \\
A_{F}=2 H \times L+D \times L+N \times \pi \times d_{p} \times L
\end{gathered}
$$

$A_{F}$ indicates the fin surface that is in contact with the fluid. The amount of $F_{F}$ for solid fins is higher than that for perforated ones due to lower amount of $A_{F}$.

The drag pressure is calculated as follows:

$$
\begin{gathered}
F_{P}=\left(-\sum P_{i} \times A_{p}\right)_{U S}-\left(-\sum P_{i} \times A_{p}\right)_{D S} \\
A_{P}=D \times H-N \times \frac{\pi d_{p}^{2}}{4}
\end{gathered}
$$

where, $A_{P}$ is frontal area of the fin. Total drag is the summation of pressure and friction drag forces:

$$
F_{D}=F_{F}+F_{P}
$$


where, $\vec{U}$ is the velocity vector, $\rho$ is the density, $\mathrm{p}$ is the pressure, $\mathrm{T}$ is the temperature, $C_{P}$ is specific heat capacity, and $k_{f}$ is thermal conductivity. It is assumed that there is no heat loss viscosity. Physical characteristics of the fluid (air) are constant during the simulations. Fluid is Newtonian and the force due to gravity is neglected. It is also considered that the effect of radiation can be ignored. The temperature field on the outer surface of block and perforations are obtained to solve the Fourier's heat conduction equation simultaneously with forced convection in the fluid.

The Navier-Stokes equations are solved by the control volume method. Also, the SIMPLE technique is used to couple the velocity and pressure fields. For discretization of momentum and energy equations, the second order upwind is used.

Fins are considered to be made of aluminum with thermal conductivity of $202 \mathrm{w} / \mathrm{mk}$. The Reynolds number is in the range of 100 and 350 results in laminar flow over the fins. The distance between fins is $10 \mathrm{~mm}$. The longitudinal perforated fins have length, width and height of 24,4 and $12 \mathrm{~mm}$, respectively. Moreover, the air velocity is such that forced convection is the dominant heat transfer mechanism between fins and the ambient air because corresponding Richardson number $\left(\mathrm{Gr} / R e^{2}\right)$ based on the fin height is less than 1 . Because of the similarity, a sample part of the fin is investigated instead of its whole parts. For $a b c d$ surface of the entrance boundary, $u_{i n}=u_{\infty}, v_{i n}=w_{i n}=0$ and $T_{i n}=T_{\infty}$. The surface named $i j k l$ is the output surface and temperature and velocity gradients in the $x$-direction are zero. The surface of efgh has constant temperature of $70^{\circ} \mathrm{C}$ and $f g l i$ and adeh surfaces are adiabatic. Also, the surfaces named $a b j i$ and $d c k l$ have symmetry boundary condition. The air temperature is $25^{\circ} \mathrm{C}$.

Radiation heat transfer is 5 to 8 percent of the whole heat transfer on the aluminum polished surface and has temperature difference of 40 to $77.5^{\circ} \mathrm{C}$. Hence, in the present study, the effect of radiation heat transfer can be neglected.

The boundary surfaces should be far enough away from the fin to ensure that the results are not affected by the surfaces. Several simulations were performed and it was found that $15 \mathrm{D}$ for input, 30D for output, $7 \mathrm{H}$ in the y-direction and 5D in the z-direction are far enough away from the fin.

We showed in a previous publication [10] that a computational domain with $70 \times 80 \times 210$ grid points is sufficient to predict the heat and fluid flow characteristics. Also, in order to check the validity of the simulations, an array of rectangular fins including rectangular perforations was considered and validated with experimental results. The related validity tests are also presented in [10].

\section{RESULTS AND DISCUSSION}

where $\bar{h}$ and $\overline{\tau_{w}}$ are the average heat transfer coefficient and the average wall shear stress over the fin side surface, respectively. It is known that the amount of average Nusselt number for circular perforated fins is higher than that of rectangular ones [10]. It also has been also found that the entrance fully developed length for the case of circular perforation is larger than that for rectangular one leads to higher heat transfer rate. We showed that the percentage of weight reduction of perforated fins in comparison with the solid one depends on the number of perforations. Hence, it is found that 1,2, 3, and 4 perforations (correspond to the porosity of $0.0555,0.111,0.1665$, and 0.222 , respectively) leads to $5.56,11.08,16.62$, and 22.16 percentage of weight reduction. In the other words, the porosity of 0.222 is the optimum case results in highest effectiveness. The aim of this paper is to evaluate the heat transfer and hydrodynamic characteristics of laminar forced convection for the optimum amount of 0.222 . Considering the thickness of the fin, creation of one perforation is not possible, so the number of perforations would be considered between 2 to 6 .

Fig. 2 shows the average friction coefficient as a function of Reynolds number for a fin with the porosity of $\varphi=0.222$. The results show that the average coefficient of friction reduces with increasing the Reynolds number and the number of perforations.

The average Nusselt number versus the Reynolds number is presented in Fig. 3. It is found that as the Reynolds number increases, the average Nusselt number increases. Also, the average Nusselt number is a decreasing function of the perforations number. Because of the perforation, a part of flow passes through the perforation leads to a reduction of mass flow over the fin. Also, the perforations generate two wakes behind the fin [10]. The Nusselt number reduces due to the separation region at the rear position of the fin. 


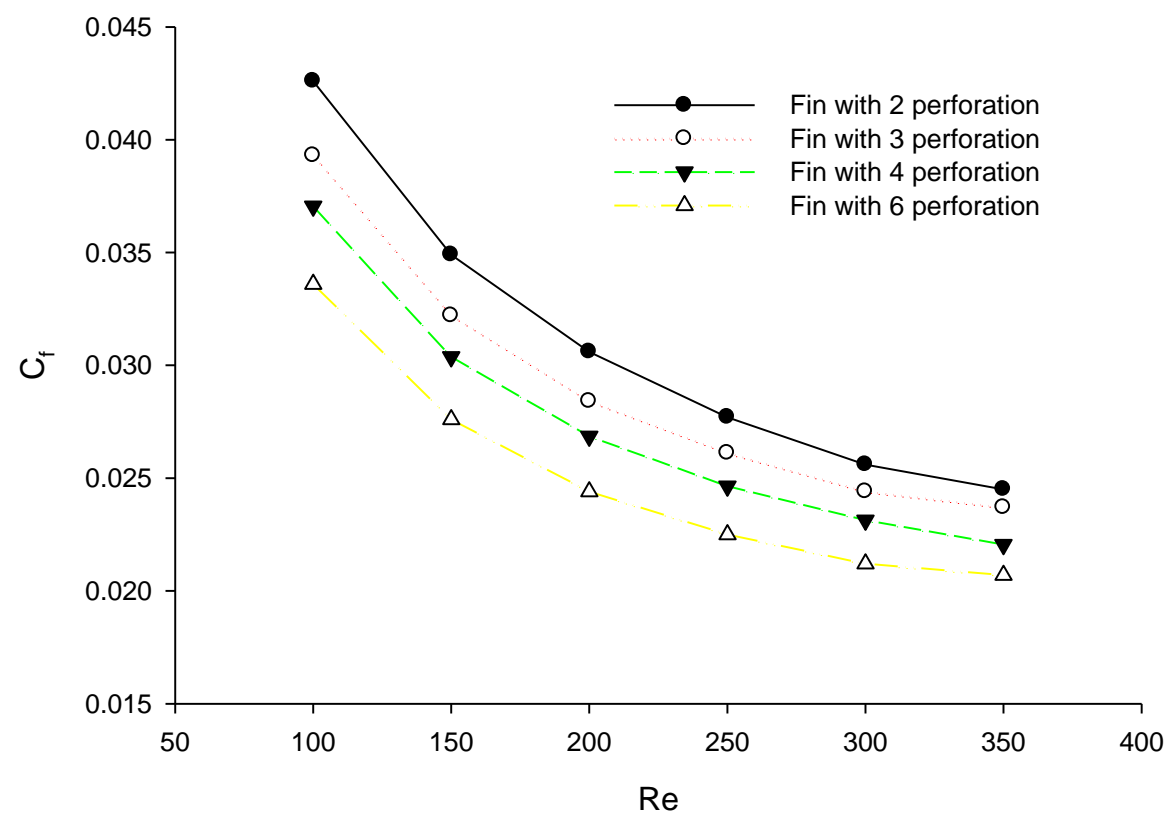

Figure 2. The average friction coefficient versus the Reynolds number at $\varphi=0.222$.

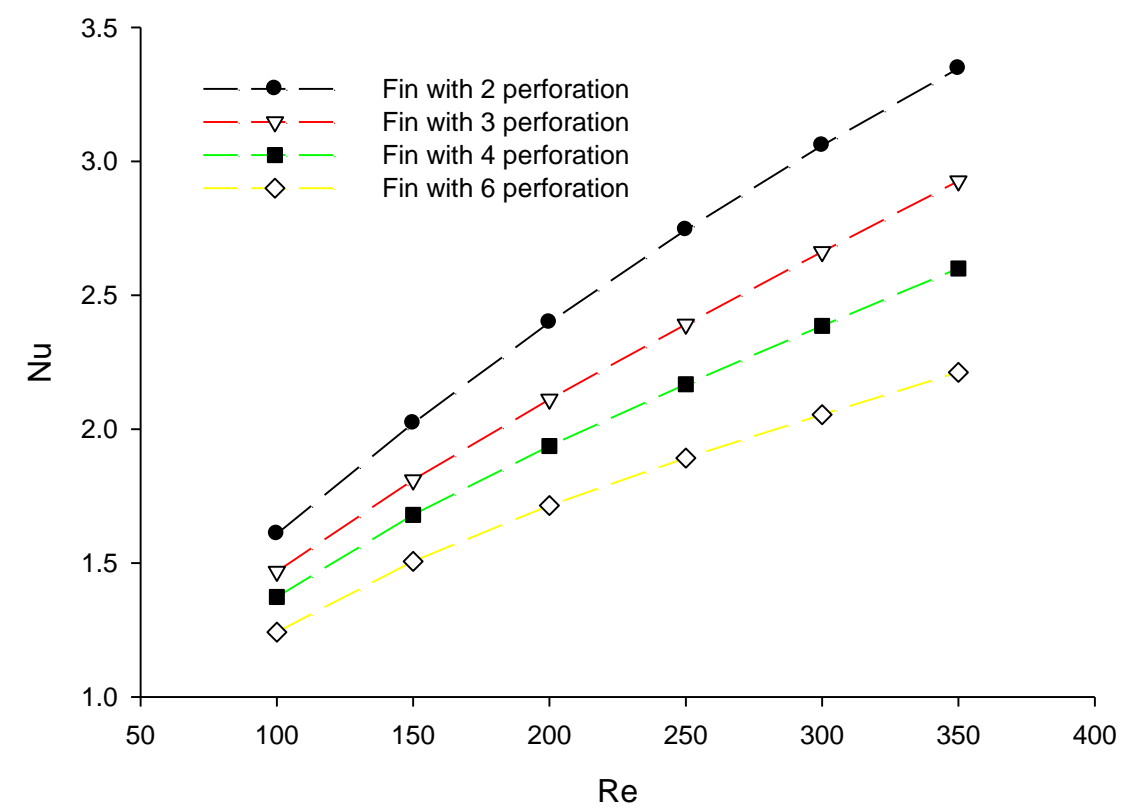

Figure 3. The average Nusselt number versus the Reynolds number at $\varphi=0.222$.

where, $Q_{p f}$ and $Q_{s f}$ indicate the rate of heat transfer for the case of perorated and solid fins, respectively. Perforated fin effectiveness is plotted as a function of Reynolds number in Fig. 4. This figure illustrates that $\varepsilon_{p f}$ decreases with the number of peroration at constant Reynolds numbers. The increase of perforations number at constant porosity leads to an increase in conduction resistance and therefore a reduction in heat transfer. Also, it is found that as the Reynolds number increases, the heat transfer increases.

The heat transfer in unit volume of the fin is plotted as a function of Reynolds number in Fig. 5 at $\varphi=$ 0.222 . As the Reynolds number increases, the flow velocity increases results in an increase in heat transfer rate. The ratio of heat transfer in circular perforated fins is higher than that in the rectangular ones. As the Reynolds number increases, the difference between their heat transfers increases. This is due to higher heat transfer coefficient of a circular perforated fin compared to that of a rectangular one. 


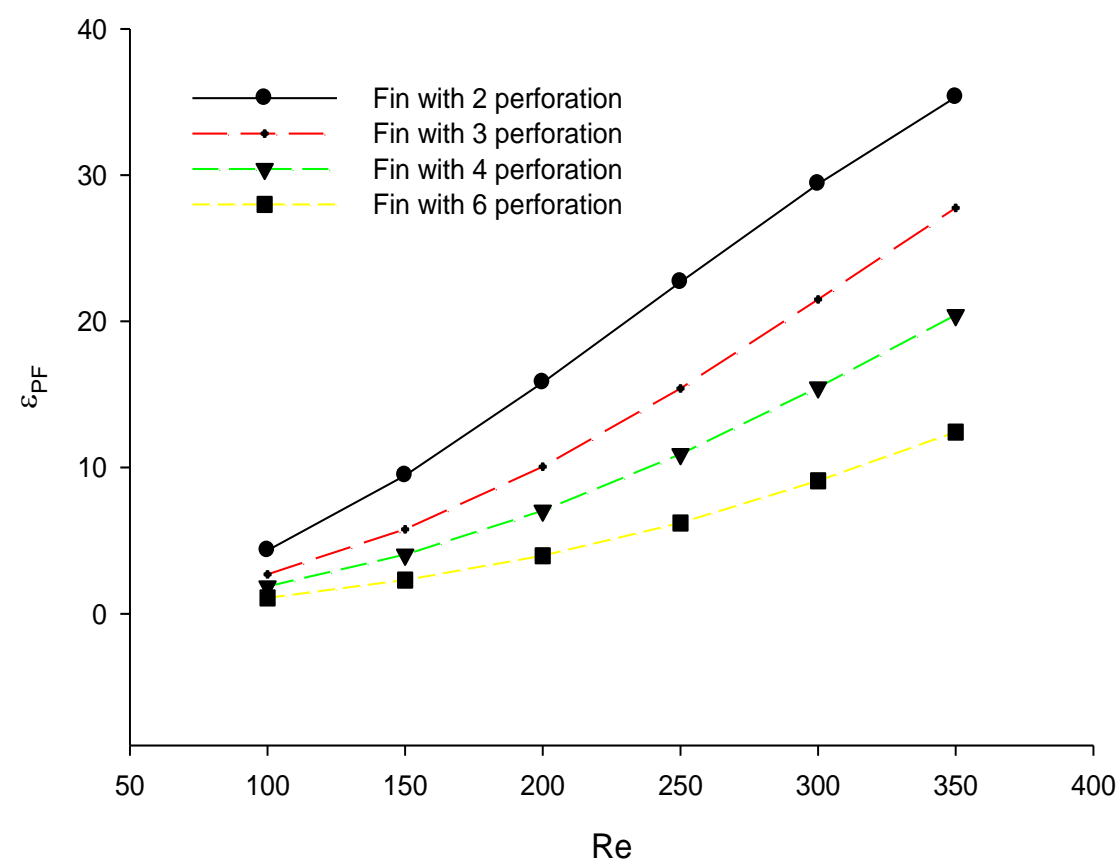

Figure 4. Perforated fin effectiveness versus the Reynolds number at $\varphi=0.222$.

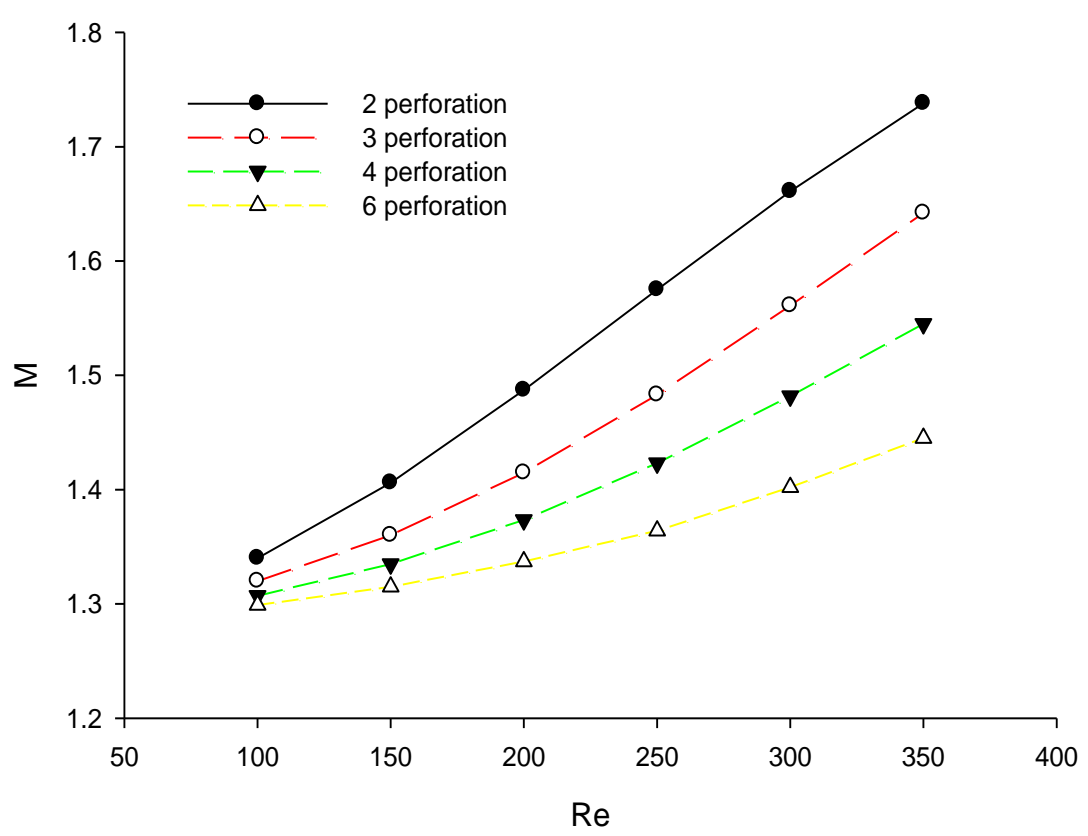

Figure 5. Changes of heat transfer per unit volume of fin as a function of the Reynolds number at $\varphi=0.222$.

Fig. 6 shows the total drag force versus Reynolds number for different perforation numbers. It is revealed that the perforation number has no significant effect on total drag force at low Reynolds numbers. The variation of total drag force is considerable at high Reynolds numbers due to large inertial effect. As the Reynolds number increases, both the frictional and pressure drag increase due to the increase in shear stress and pressure difference, respectively. 


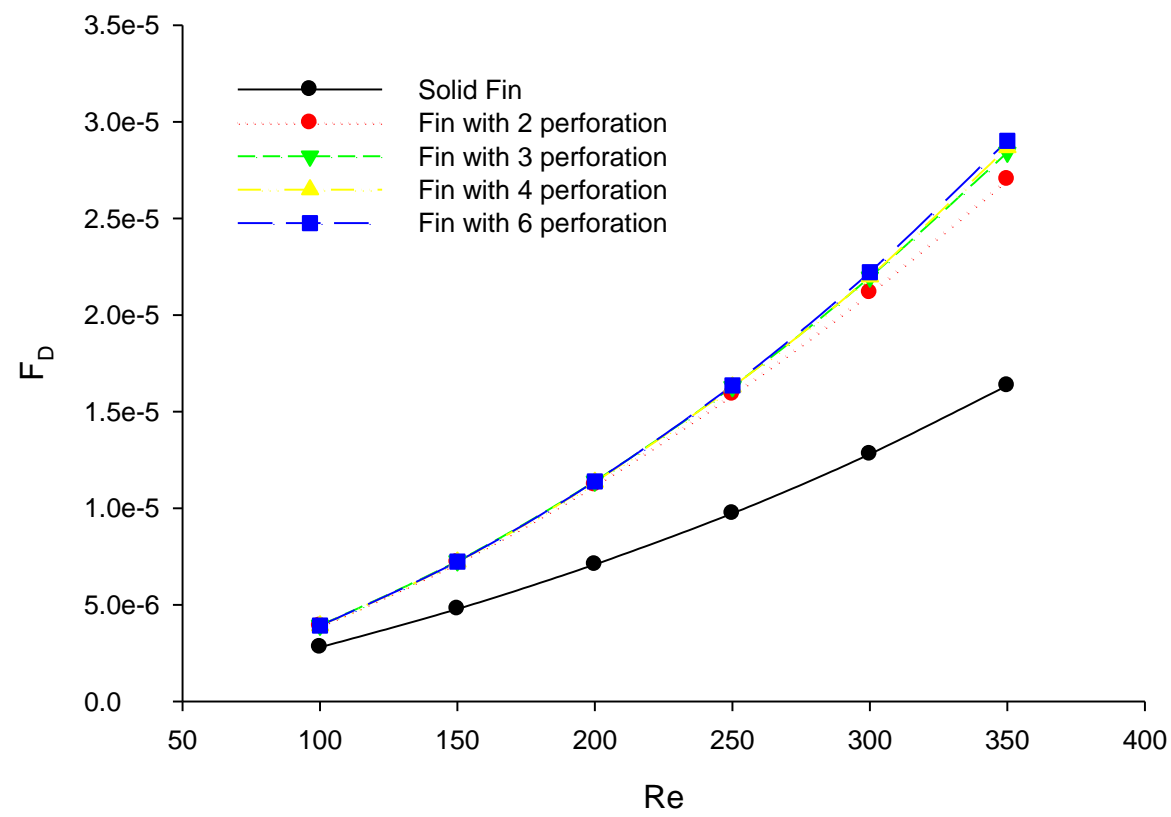

Figure 6. Variation of total drag force in the flow direction versus the Reynolds number at $\varphi=0.222$.

\section{CONCLUDING REMARKS}

Laminar convection heat transfer from a heated array of circular perforated fins was studied numerically. The Navier-Stokes and energy equations were solved by a finite volume method using the SIMPLE algorithm. The results showed that as the Reynolds number and the number of perforation increases, the average coefficient of friction decreases. It is demonstrated that the average Nusselt number increases with the Reynolds number at constant porosity. Also, the average Nusselt number is a decreasing function of the perforations number. Perforated fin effectiveness decreases with the number of peroration at constant Reynolds numbers. It is also found that the perforation number has no significant effect on total drag force at low Reynolds numbers, but has larger effect at high Reynolds numbers.

\section{NOMECLATURE}

$\mathrm{A}_{\mathrm{p}} \quad$ Frontal area

$\overline{\mathrm{C}_{\mathrm{f}}} \quad$ Average friction coefficient

D Fin thickness [m]

$\mathrm{d}_{\mathrm{P}} \quad$ Perforation diameter $[\mathrm{m}]$

$\mathrm{F}_{\mathrm{D}} \quad$ Total drag

$\mathrm{F}_{\mathrm{F}} \quad$ Frictional drag

$\mathrm{F}_{\mathrm{p}} \quad$ Pressure drag

Gr Grashof number

$\overline{\mathrm{h}} \quad$ Average convection heat transfer coefficient $\left[\mathrm{W} / \mathrm{m}^{2} \mathrm{~K}\right]$

$\mathrm{H} \quad$ fin height $[\mathrm{m}]$

$\mathrm{H}_{\mathrm{P}} \quad$ Distance between perforation center and fin base [m]

$\mathrm{L}$ fin length [m]

$\mathrm{N}$ number of perforations

$\overline{\mathrm{Nu}} \quad$ average Nusselt number

M heat transfer of unit volume coefficient

$\mathrm{P}$ pressure $[\mathrm{Pa}]$

Q Heat transfer rate from fin surface [W]

Re Reynolds number

$\mathrm{T}$ temperature $[\mathrm{K}]$

$\mathrm{u}, \mathrm{v}, \mathrm{w} \quad$ velocity components in $x, y, z$-directions $[\mathrm{m} / \mathrm{s}]$

$\mathrm{V}_{\mathrm{S}} \quad$ fin volume $[\mathrm{L} \times \mathrm{D} \times \mathrm{H}]$

$\mathrm{V}_{\mathrm{p}} \quad$ Perforated fin volume $\left[\frac{\pi d_{p}^{2}}{4} \times L\right]$

w $\quad$ Fin width $[\mathrm{m}]$ 


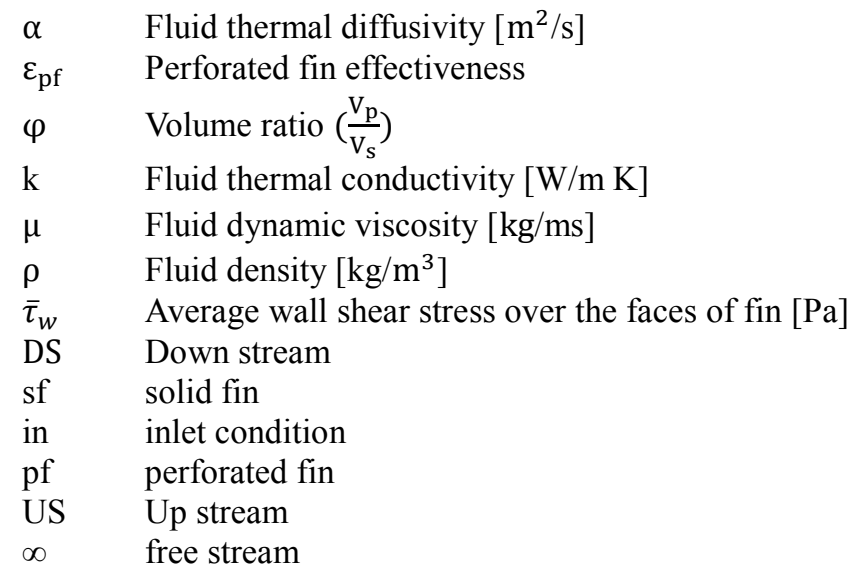

\section{REFERENCES}

[1] Q. D. Kern, D. A. Kraus. (1972). Extended surface heat transfer, New York, McGraw-Hill.

[2] Arslanturk, C., Ozguc, A. F. (2006). Optimization of a central-heating radiator. Applied energy, 83(11), 11901197.

[3] El-Sayed, S. A., Mohamed, S. M., Abdel-latif, A. A., Abdel-hamid, E. A. (2004). Experimental study of heat transfer and fluid flow in longitudinal rectangular-fin array located in different orientations in fluid flow. Experimental Thermal and Fluid Science, 29(1), 113-128.

[4] Sahin, B., Demir, A. (2008). Performance analysis of a heat exchanger having perforated square fins. Applied Thermal Engineering, 28(5-6), 621-632.

[5] Dhanawade, K. H., Sunnapwar, V. K., Dhanawade, H. S. (2016). Optimization of Design Parameters for Lateral Circular Perforated Fin Arrays under Forced Convection. Heat Trans. Asian Res, 45, 30-45.

[6] Rawat, K., Patil, A. K. (2016). Heat Transfer and Friction Characteristics of Perforated Fin with a Longitudinal Slot under Forced Convection. Heat Transfer-Asian Research, 45(6), 536-555.

[7] Saadat, H., Tavakol, M. M., Yaghoubi, M. (2014, November). Experimental study on heat transfer from a perforated fin array with cross perforations. In The 2nd Heat and Mass Transfer Conference.

[8] Ismail, M. F., Reza, M. O., Zobaer, M. A., Ali, M. (2013). Numerical investigation of turbulent heat convection from solid and longitudinally perforated rectangular fins. Procedia Engineering, 56, 497-502.

[9] Shaeri, M. R., Yaghoubi, M. (2009). Numerical analysis of turbulent convection heat transfer from an array of perforated fins. International Journal of Heat and Fluid Flow, 30(2), 218-228.

[10] Ashjaee, M., Goharkhah, M., Khadem, L. A., Ahmadi, R. (2015). Effect of magnetic field on the forced convection heat transfer and pressure drop of a magnetic nanofluid in a miniature heat sink. Heat and Mass Transfer, 51(7), 953-964.

[11] Shaeri, M. R., Bonner, R. (2017, July). Effect of Perforation Size to Perforation Spacing on Heat Transfer in Laterally Perforated-Finned Heat Sinks. In ASME 2017 Heat Transfer Summer Conference (pp. V002T14A005V002T14A005). American Society of Mechanical Engineers.

[12] Wen, M. Y., Yeh, C. H. (2017). Numerical study of thermal performance of perforated circular pin fin heat sinks in forced convection. Heat and Mass Transfer, 53(6), 2031-2044.

[13] Mohammadi, S., Ahmadi Nadooshan, A., Bayareh, M. (2017). Numerical simulation of laminar convection heat transfer from an array of circular perforated fins. Energy Equipment and Systems, 5(2), 147-156.

[14] Bayareh, M., Pordanjani, A. H., Nadooshan, A. A., Dehkordi, K. S. (2017). Numerical study of the effects of stator boundary conditions and blade geometry on the efficiency of a scraped surface heat exchanger. Applied Thermal Engineering, 113, 1426-1436.

[15] Maurya, R. S., Singh, S. (2017). Numerical Investigation of Isothermal Flow around Impingement Plates in a Shell and Tube Exchanger. Journal of Thermal Engineering, 3(5), 1442-1452. 